\title{
Acoustic Emission Characteristics of Compressive Deformation and Failure of Siltstone under Different Water Contents
}

\author{
Lei Chen, Jian Zhao, and Zhiyang Zheng \\ Faculty of Resource and Safety Engineering, China University of Mining and Technology, Beijing 100083, China \\ Correspondence should be addressed to Lei Chen; chenlei@cumtb.edu.cn
}

Received 5 December 2016; Revised 17 February 2017; Accepted 6 March 2017; Published 10 April 2017

Academic Editor: Antonio Riveiro

Copyright (C) 2017 Lei Chen et al. This is an open access article distributed under the Creative Commons Attribution License, which permits unrestricted use, distribution, and reproduction in any medium, provided the original work is properly cited.

\begin{abstract}
The uniaxial compression and acoustic emission (AE) monitoring of siltstone specimens in the Gongchangling open-pit iron mine in Liaoning Province was conducted by evaluating the effects of three water saturation levels: dry, natural, and water-saturated. The siltstone AE characteristics were analyzed according to water content; the relationship between the AE characteristics and the growth and expansion of siltstone cracks was subsequently discussed. Research results indicated the following: siltstone specimens had distinctly different mechanical properties and AE characteristics according to water content; as the water content increased the compressive strength and elasticity modulus of specimens decreased. In the compacting phase of specimens under compression, the $\mathrm{AE}$ count rate of the water-saturated specimen was relatively small and the events were relatively stable. In the linear-elastic deformation phase, the AE count rate of the dry specimen increased sharply, reaching approximately 400 times/s. In the plastic yield deformation phase, the peak value of the AE count rate of the dry specimen ranged between 955 and 1,068 times/s, whereas that of the water-saturated specimen only attained a range of 635 to 782 times/s. In the failure phase, the time to reach the peak stress value of the dry specimen was increased as compared to that of the AE count rate.
\end{abstract}

\section{Introduction}

Under the effects of an external load, microfissures and other deformations within rocks gradually expand, thus bringing about macrodeformation. During this process, acoustic emission (AE) occurs. These transmitted signals are released in the form of acoustic waves and are able to reflect the mechanical properties of rocks. The growth and expansion status of internal cracks can be studied by acquiring and analyzing the acoustic waves transmitted during rock deformation. In the 1930s, Obert and Duvall observed that the AE phenomenon accompanied rock failure under compression, subsequently applying this finding to monitor and forecast rock explosion [1-3]. Many foreign and domestic scholars have studied rock deformation [4-6], the damage and stress memory effects of sandstone [7], the crack expansion rule during the rock failure process [8-10], the fracture instability mechanism and outburst proneness of coal and rock mass [11-14], the mechanical properties of lamprophyre upon encountering water [15], and the mechanical properties of various other rocks via the $\mathrm{AE}$ technique.
In engineering practice, a variation in rock water content will bring about profound differences in the mechanical properties of rocks, with studies showing that water-rock interaction is an important factor in these differences [16-18]. Some scholars studied and analyzed the causes of the softening phenomenon of soft rocks upon encountering water [1922]. Heggheim et al. [23] studied the mechanism of the saline solution-softening limestone. Yang et al. [24] analyzed the causes of changes in mechanical properties of slate by comparing its microstructures before and after encountering water. Voznesenskii et al. [25] studied the acoustic mechanism of salt rock during the dissolution process upon encountering water.

In slope engineering, particularly in the fields of water conservancy, transportation, and mining, siltstone is commonly used for research where its strength and stability under load are discussed. Studying the influence of water content on siltstone failure and its strength characteristics under compression by combining the $\mathrm{AE}$ technique is of important theoretical significance and engineering application value. To study the instability mechanism of rock masses, the following 
were performed: (1) a uniaxial compression test of siltstone specimens exposed to three differing water contents: dry, natural, and water-saturated conditions; (2) a collection and characteristics analysis of $\mathrm{AE}$ signals during specimen compression; and (3) an investigation into the respective relationships between $\mathrm{AE}$ characteristics and cracking and the expansion and coalescence process of in situ microcracks of siltstone according to water content.

\section{Materials and Methods}

2.1. Specimen Acquisition and Processing. Rock specimens were taken from the Gongchangling open-pit iron mine in Liaoning Province. To prevent water evaporation and weathering caused by prolonged exposure, specimens were wrapped with multilayer preservative films. The large rocks taken from the site were processed into several standard cubic rock blocks of $50 \mathrm{~mm}$ length, $50 \mathrm{~mm}$ width, and $100 \mathrm{~mm}$ height, in accordance with the requirements of the Rock Experimental Regulations in Water Resources and Hydropower Engineering.

\subsection{Experimental Equipment and Methods. The TAW-3000} servo press was used to conduct uniaxial compression testing. The data acquisition system consisted of a displacement sensor, a stress sensor, and a strain gauge to measure rock deformation. The loading mode was the displacement control, and the loading rate was $0.2 \mathrm{~mm} / \mathrm{min}$. The PCI- $2 \mathrm{AE}$ monitoring system was used for $\mathrm{AE}$ acquisition; this system could realize real-time data acquisition and analysis functions under the Windows environment. The standard specimens were separated into three groups after processing. The first group included specimens that were sufficiently dried, the second group included specimens that were in their natural state, and the third group included water-saturated specimens. The specimens in the first and second groups were placed in a GZX-9070MBE drying oven to maintain constant-temperature drying for $100 \mathrm{~h}$ at $105^{\circ} \mathrm{C}$. For Group 3, a free soaking method was used to saturate the specimens. Three compact rock blocks with uniform textures were taken from each group. The rock block parameters are shown in Table 1. The specimens and experimental equipment are shown in Figures 1(a), 1(b), and 1(c).

\section{Results and Discussion}

3.1. Strength and Deformation Characteristics. The stressstrain curves of the rock specimens throughout the failure process were obtained according to water content via use of the TAW-3000 servo press (Figures 2(a), 2(b), and 2(c)), which yielded the respective overall stress-strain process curves of the rocks in the dry, natural, and water-saturated states. The morphologies and peak values of the curves varied according to water content, which indicated that the differences in water content yielded different levels influence on the mechanical properties of siltstone.

Figure 2 demonstrates that the resultant stress-strain curves of the uniaxial compression of siltstone were categorized into the following four phases:
(1) Compacting phase of in situ cracks: natural microcracks or microjoints existed in the siltstone blocks, and as the axial compression increased, these opened structural surfaces gradually closed, and with the rock tending to be compact, the growing rate of stress slowed and the curves exhibited an upward concave profile. As the water content increased, the upward concave curvature became increasingly less apparent, which indicated that, upon adding an equivalent axial stress, the strain increased as water content increased, thereby implying that the water content influenced the growth of the initial internal siltstone cracks, with higher water content yielding increasingly rapid in situ crack growth.

(2) Linear-elastic deformation phase: in this phase, the stress-strain curve presented a linear ascending status, the microcracks or microjoints inside the rock were compacted, and the rock deformation changed into a linear-elastic deformation that conformed to Hooke's law. As the water content increased, the curve slope gradually decreased, which indicated that the elasticity modulus of the rock block decreased as the water content increased.

(3) Plastic yield deformation phase: in this phase, the curve exhibited an ascending tendency in the upward concave profile; that is, the curve ascended with gradual decreases in the slope until the peak value was reached. This demonstrated that as the axial stress increased, stress concentration areas appeared at the endpoints of the microcracks or microjoints. These stress concentration areas accelerated the development of microcracks, which continuously expanded until achieving surface penetration as macrocracks, thus resulting in the failure of the specimens. The long duration of this phase implied that water content altered the mechanical properties of siltstone to yield gradual softening of the rocks and plastic deformation characteristics.

(4) Fracture phase: in this phase, the curve exhibited a sharp descent after reaching the peak value, which indicated that the rock specimen fractured along the internal macrocracks and that the rock lost its bearing capacity. As the water content increased, the peak value of the curve decreased, which indicated that the water affected the strength of the siltstone and reduced the peak value stress of the rock.

Through testing and calculations, the deformation indices and mechanical parameters of the siltstone specimens according to water content were obtained as shown in Table 2.

Table 2 shows that as the water content increased, the compressive strength and elasticity modulus of the specimens decreased. The compressive strength of specimens in the natural state decreased by $47.83 \%$ as compared to the compressive strength of the specimens in the dry state; additionally, the elasticity modulus decreased by $45.74 \%$. The compressive strength of the specimens in the watersaturated state decreased by $40.2 \%$ as compared with the 


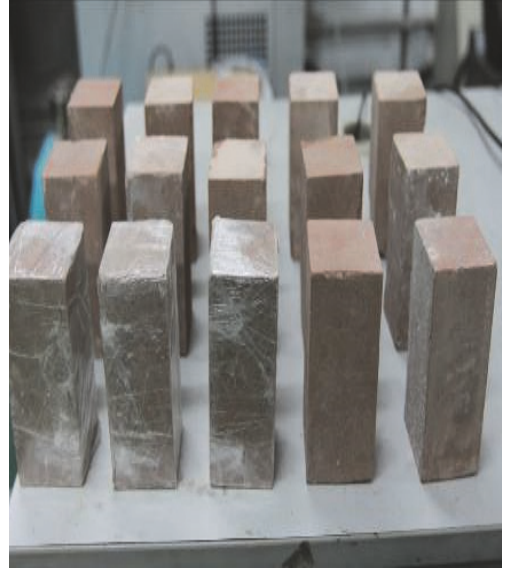

(a) Specimens

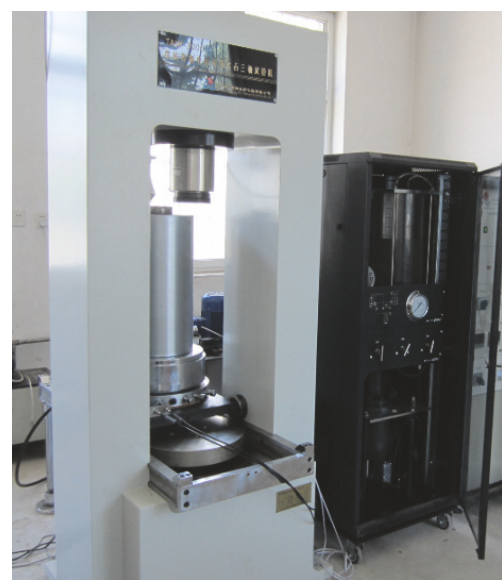

(b) Press machine

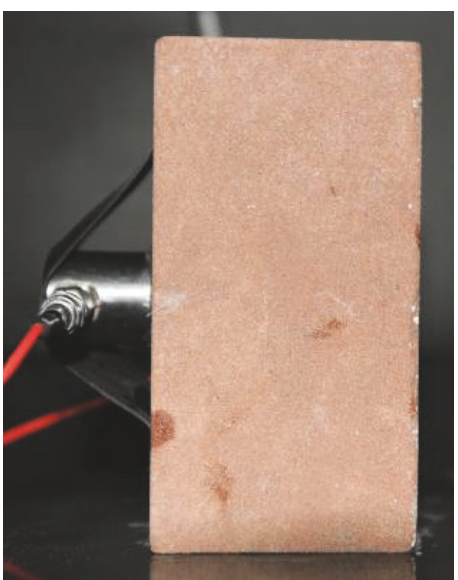

(c) AE signal

FIGURE 1: Material and methods.

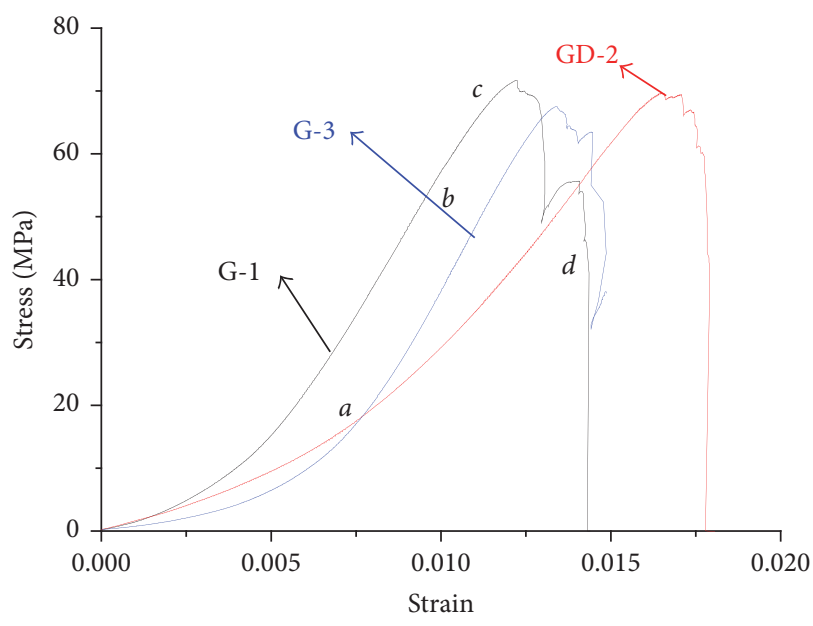

(a) Dry specimens

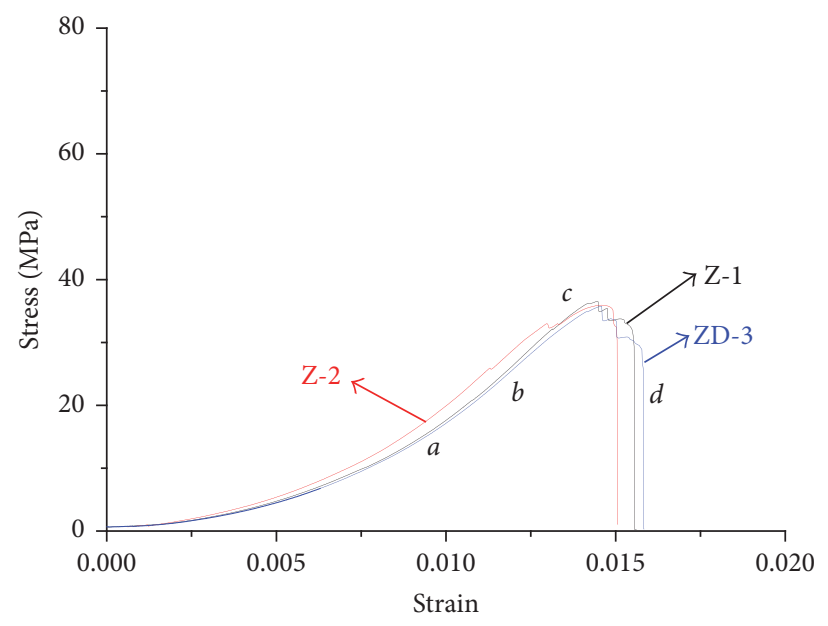

(b) Natural specimens

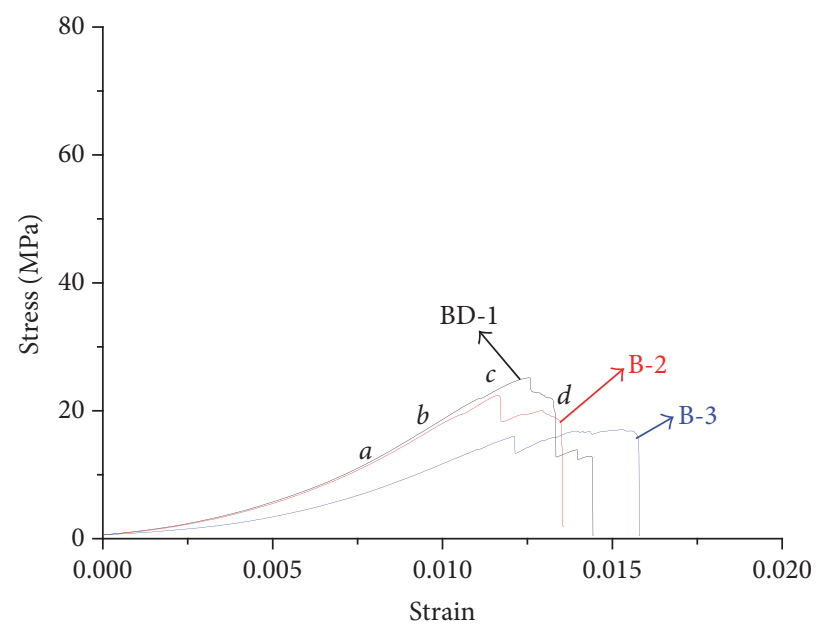

(c) Saturated specimens

FIGURE 2: Stress-strain curves of rock. 
TABLE 1: List of physical parameters.

\begin{tabular}{|c|c|c|c|c|}
\hline State & Number & Size $(l \times b \times h) / \mathrm{mm}$ & Water content $/ \%$ & Mean value $/ \%$ \\
\hline \multirow{3}{*}{ Dry } & G-1 & $49.2 \times 50.1 \times 99.8$ & 0.00 & \multirow{3}{*}{0.00} \\
\hline & G-2 & $48.3 \times 49.9 \times 100.3$ & 0.00 & \\
\hline & G-3 & $49.4 \times 50.2 \times 98.2$ & 0.00 & \\
\hline \multirow{3}{*}{ Natural } & $\mathrm{Z}-1$ & $48.9 \times 49.2 \times 99.7$ & 1.56 & \multirow{3}{*}{1.52} \\
\hline & $\mathrm{Z}-2$ & $49.8 \times 48.9 \times 100.1$ & 1.43 & \\
\hline & Z-3 & $50.1 \times 50.0 \times 100.1$ & 1.57 & \\
\hline \multirow{3}{*}{ Saturated } & B-1 & $49.5 \times 49.8 \times 99.8$ & 4.12 & \multirow{3}{*}{3.98} \\
\hline & B-2 & $50.0 \times 49.9 \times 100.1$ & 3.81 & \\
\hline & B-3 & $50.2 \times 49.5 \times 99.7$ & 4.02 & \\
\hline
\end{tabular}

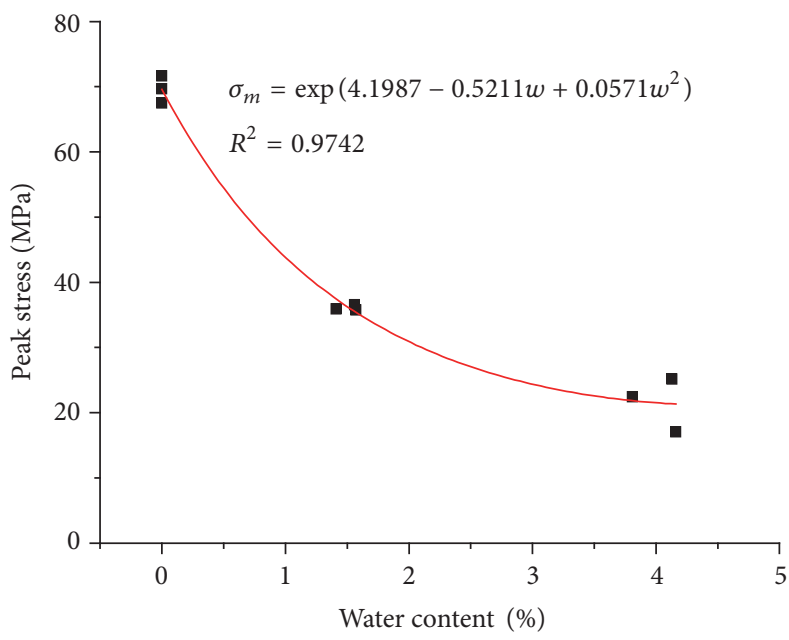

(a) Relationship between peak stress and water content

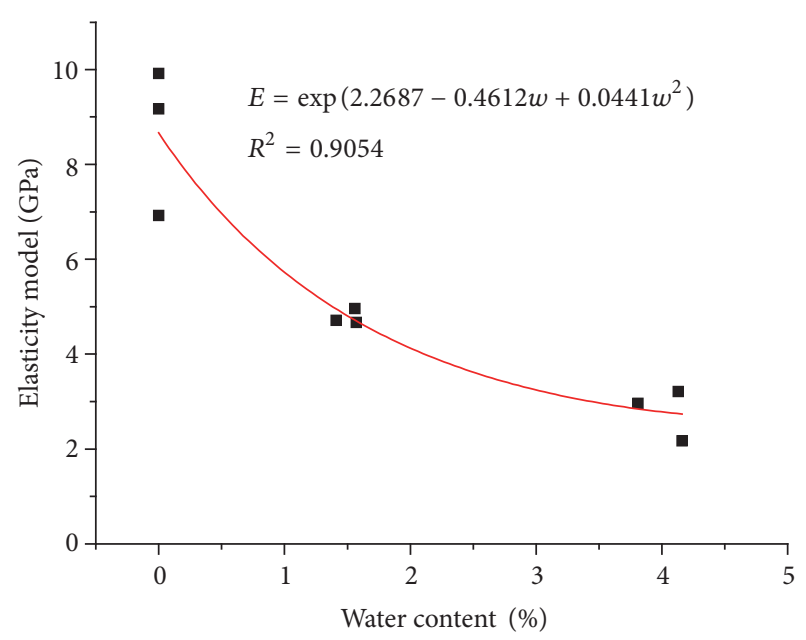

(b) Relationship between elasticity modulus and water content

FIGURE 3: Relationship between strength and water content.

compressive strength of the specimens in the natural state; additionally, the elasticity modulus decreased by $39.7 \%$. As the water content increased, the average failure time of the specimens lengthened, which indicated that the existence of water altered the mechanical properties of the siltstone, yielding an acutely distinct softening effect of water on the siltstone. The softening effect of water content on siltstone was further analyzed and relevant data in Table 2 were fitted. The respective relationship curves between the compressive strength and water content and the elasticity modulus and water content were obtained as shown in Figures 3(a) and 3(b).Figure 3 illustrates that the peak value stress and elasticity modulus of the siltstone specimen possessed exponential functional relationships with the water content and that all correlation coefficients were above 0.9 . These results are similar to the results obtained in previous studies [26-28].

3.2. Specimen Failure Modes. During the experimental process, an HD camera was used to capture the entire rock specimen fracture process; the failure modes of the specimens according to water content are shown in Figures 4(a), 4(b), and $4(\mathrm{c})$.

Figure 4 shows that, in the dry, natural, and watersaturated states, the failure modes of the specimens were nearly identical; that is, they all exhibited signs of X-type conjugated shear failure. However, although they exhibited signs of the same type of failure, the failure modes among the three different specimens were not completely identical. Before the crack coalescence in the dry specimen, many small cracks appeared with associated failure of cleaving and shear cracks, demonstrating a mixed failure of shear and tension (Figure 4(a)). The specimens in the natural state exhibited a relatively slow main crack coalescence, which is typical of X-type shear failure, and a mixed failure of tension and shear (Figure 4(b)). The X-type failure of the water-saturated specimen was not easily distinguishable, and the paralleling of joints to the vertical axis occurred in some specimens before failure, which was attributed more to tension failure during the fracture process (Figure 4(c)).

The physical phenomena of rock block fractures also yielded significant variation according to water content. The fractures in the dry rock specimens were accompanied by relatively large fracture acoustics, a large quantity of chips surrounding the main cracks, and two collapsed ends, which indicated that energy was instantly released and the specimens underwent brittle failure. The main crack coalescence in the natural specimens was relatively slow, with some chips immediately adjacent to the area of fracture undergoing 

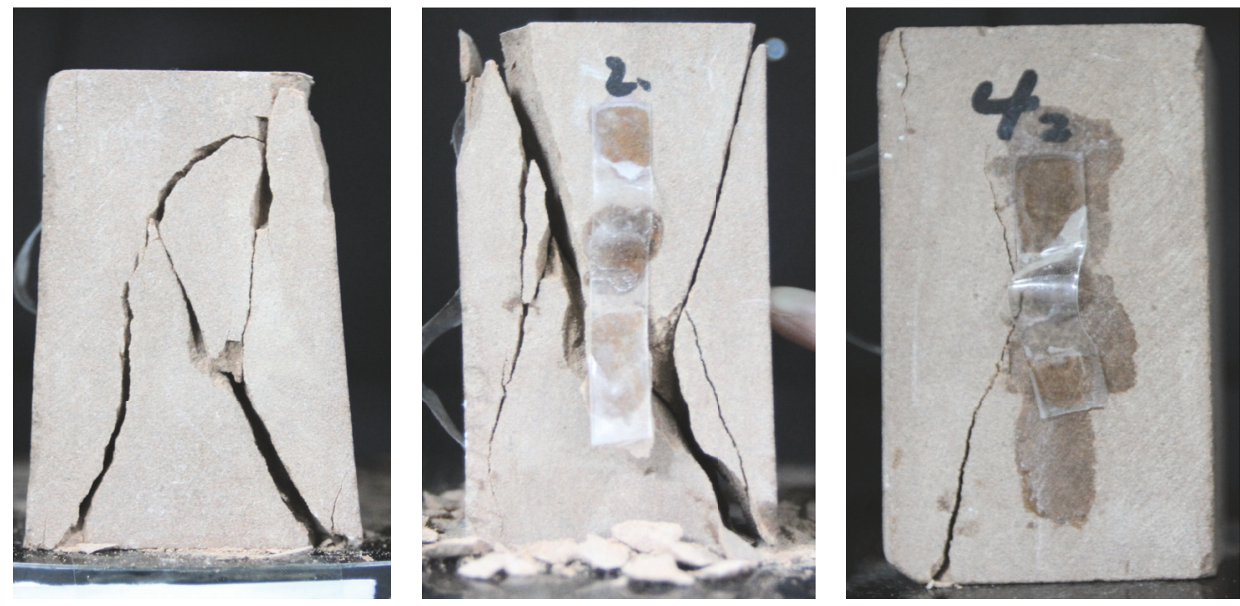

(a) Dry specimens
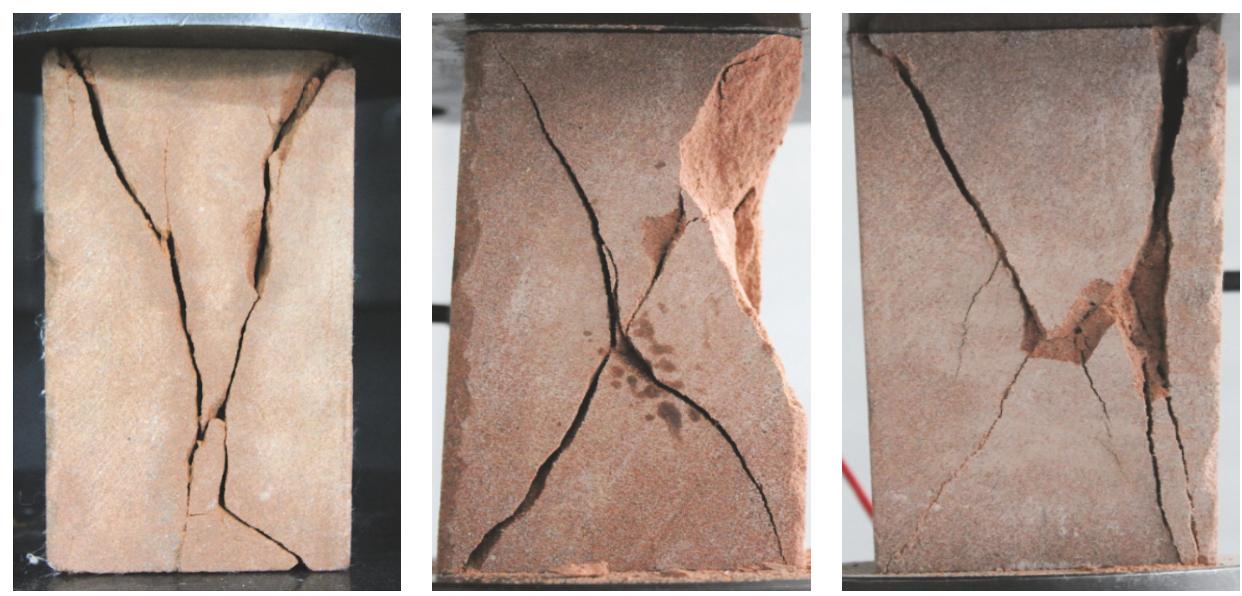

(b) Natural specimens
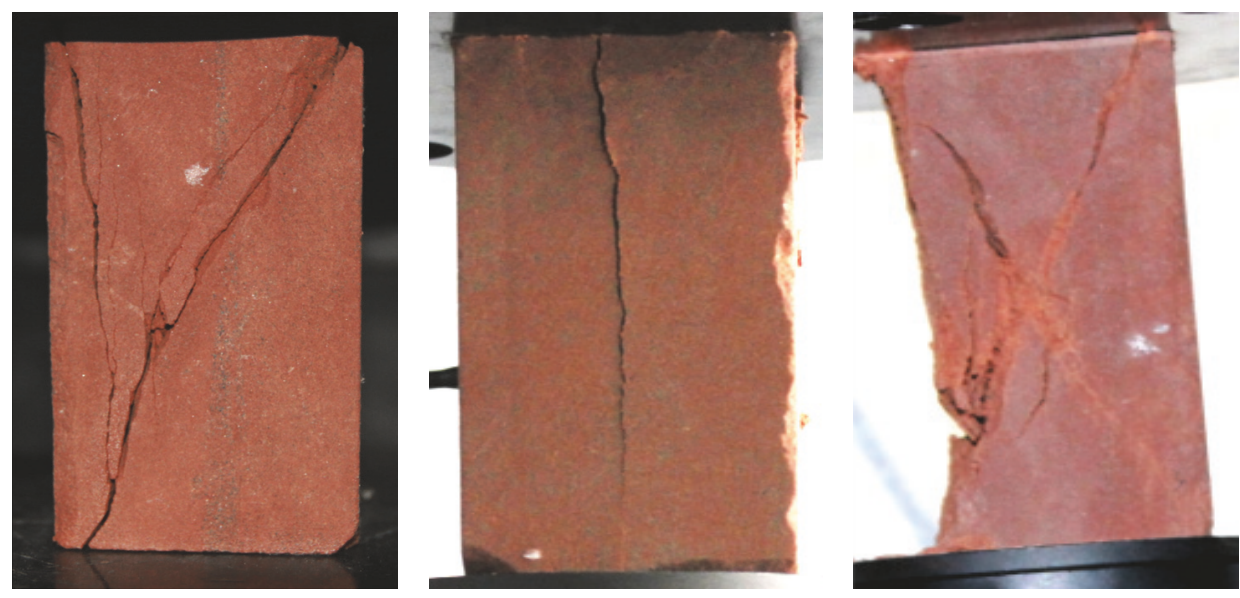

(c) Saturated specimens

FIGURE 4: Fracture patterns of specimens with differing moisture contents. 


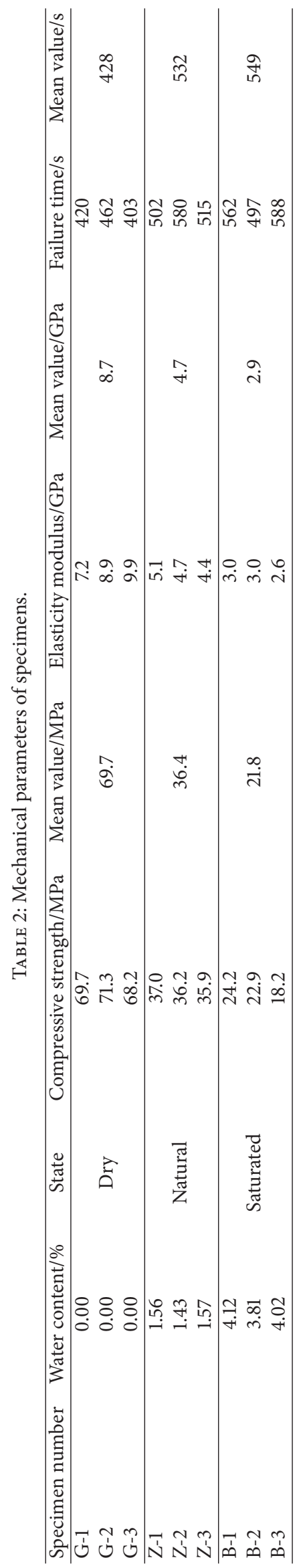




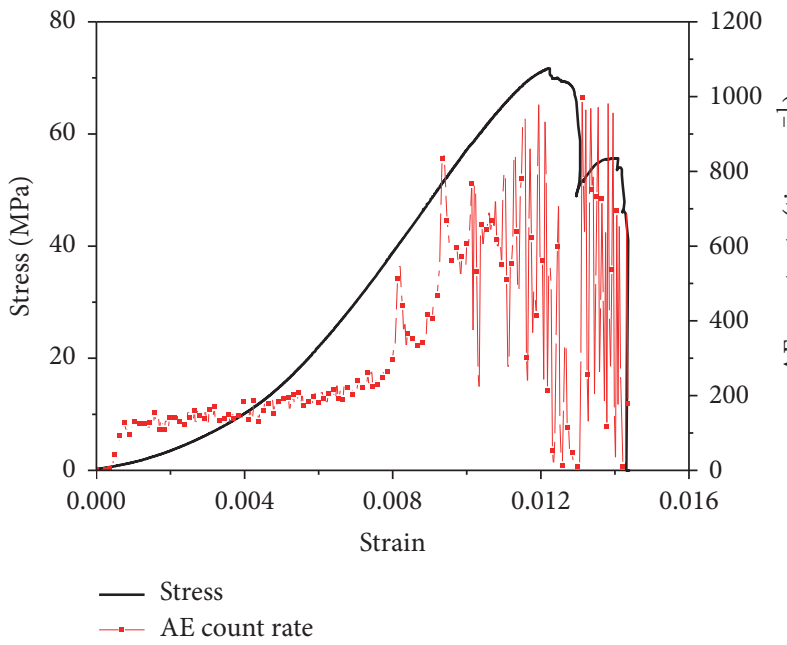

(a) G-1

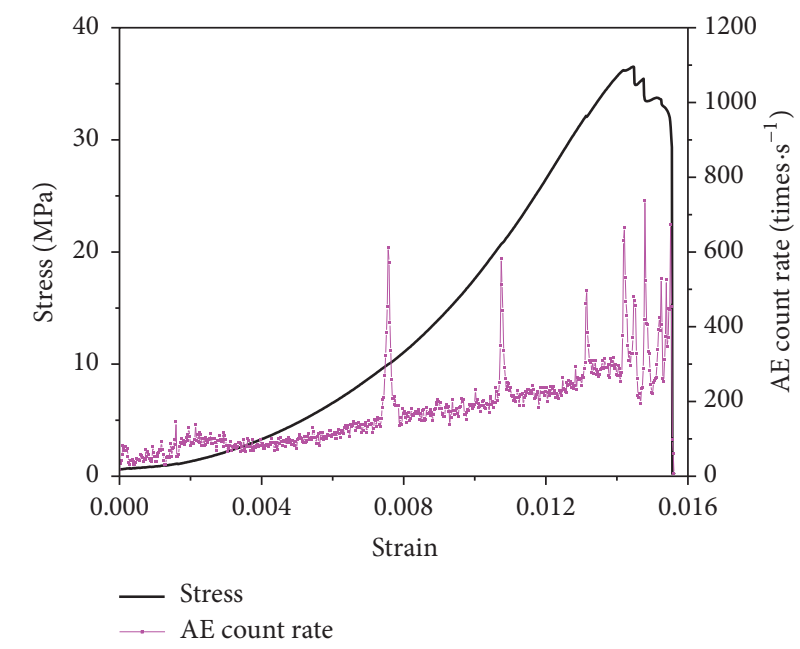

(b) Z-2

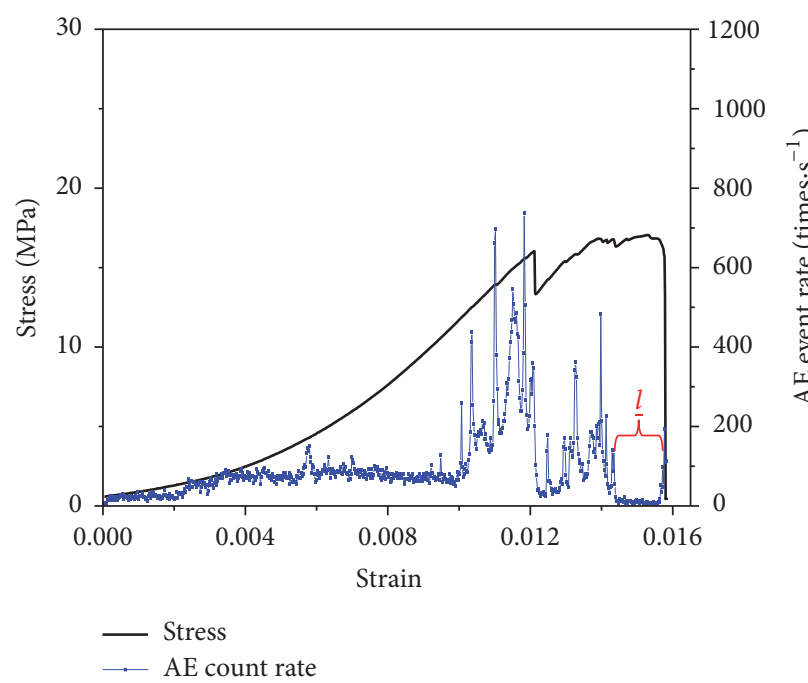

(c) B-3

FIGURE 5: Stress-AE count-strain curves of specimens.

a collapse that was not violent. The fracture acoustics in the water-saturated specimens were low, with only a marginal amount of chips collapsing around the main crack, which indicated that the energy was nearly uniformly released throughout the period of saturation leading up to failure; the specimen failure exhibited a plastic failure tendency.

To summarize the above analyses, the main crack coalescence of the rock specimens slowed as the water content increased. Moreover, the severity of specimen failure tended to be reduced, which indicated that the water exerted a softening effect on the siltstone, thereby causing the failure of the specimen to change from brittle to plastic failure.

3.3. Characteristics of the AE Count Rate. Uniaxial compression testing was conducted on siltstone specimens, while the PCI-2 AE testing system was used to acquire AE signals during rock block fractures. After the acquired data were processed, the following relationship curves were obtained according to water content: (1) stress and strain, (2) $\mathrm{AE}$ count rate and strain, and (3) total AE count and strain of specimens; this is demonstrated using the G-1, Z-2, and B-3 specimens as examples, as shown in Figures 5(a), 5(b), 5(c) and $6(\mathrm{a}), 6(\mathrm{~b}), 6(\mathrm{c})$.

Figures 5 and 6 show that AE signals were generated from within the siltstone specimens throughout the entire uniaxial compression process until failure occurred, that the stress-strain relationship curves between the change in $\mathrm{AE}$ count rate and specimens were consistent, and that the maximum value of $\mathrm{AE}$ count rate was near the peak stress value. The total $\mathrm{AE}$ count curves had the same tendency and approximate shape as the stress-strain curves, which indicated that the $\mathrm{AE}$ count rate could characterize the compressive failure process of rocks; this finding is similar to that found in previous studies [25, 29-32].

The AE count rate also yielded the following variations according to water content: 


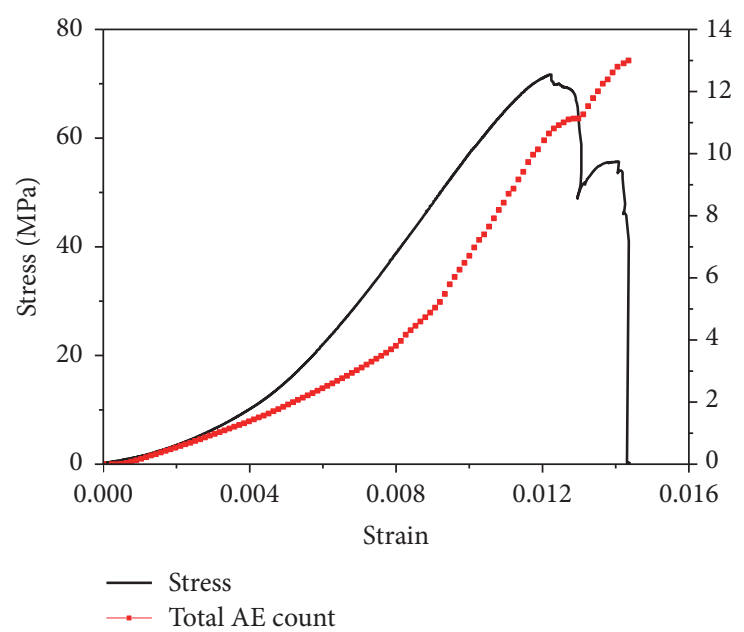

(a) G-1

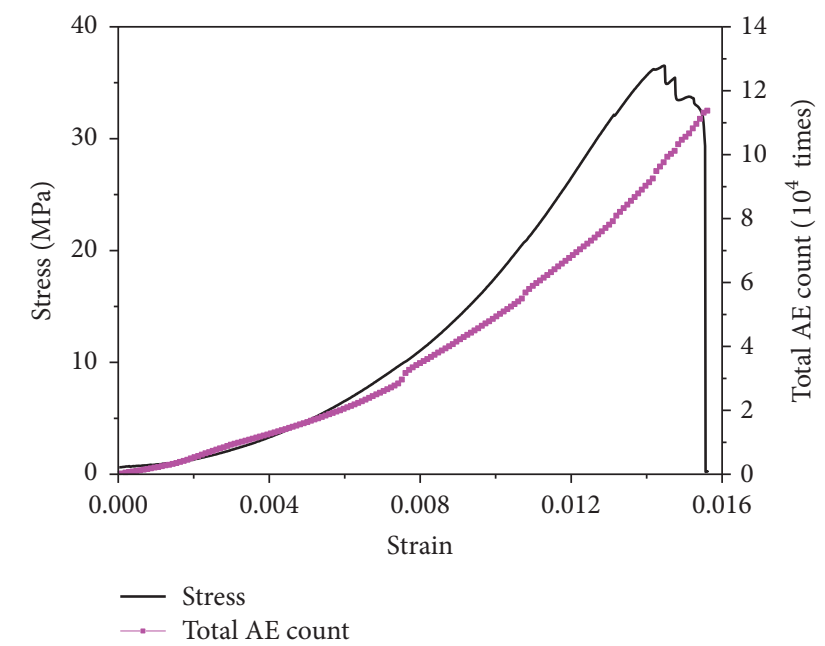

(b) Z-2

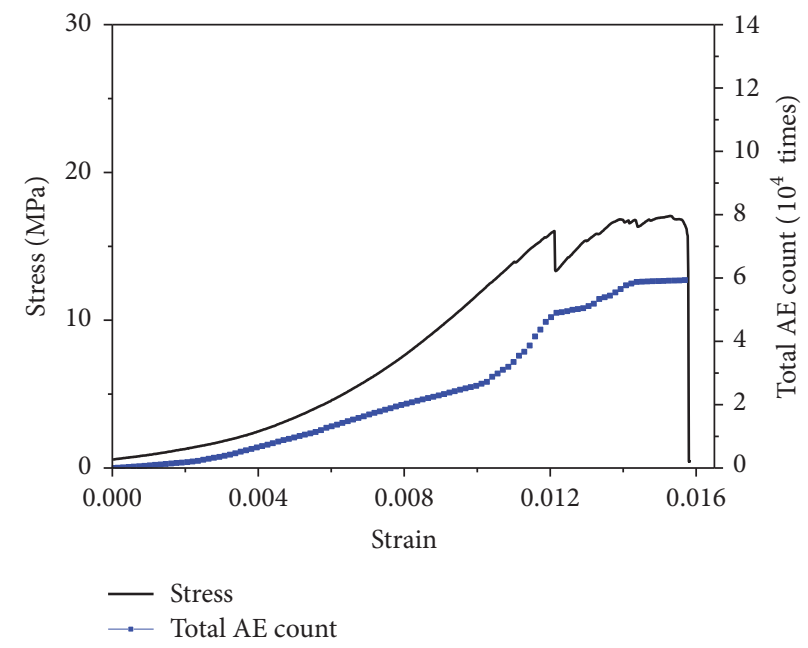

(c) B-3

FIGURE 6: Stress-total AE count-strain curves of specimens.

(1) In the compacting phase of in situ cracks, the existence of natural cracks in the rock when compressed generated $\mathrm{AE}$ signals. However, the $\mathrm{AE}$ count rates in the water-saturated specimens were low, with the primary reason being that water filled the natural cracks, thereby decreasing the rock void ratio and lessening the failure severity of rock specimens.

(2) In the linear-elastic deformation phase, the rock exhibited elastic deformation, internal cracks exhibited only marginal expansion, the AE count rates were relatively stable, the $\mathrm{AE}$ count rates of specimens in the dry state exhibited sudden increases, with numbers reaching approximately 400 times/s before stabilizing, and the AE count rates of specimens containing water were less than those of the dry specimens.

(3) In the plastic yield deformation phase, the AE count rates increased rapidly at a rate of 3-6 times that of the linear-elastic phase, which indicated that the internal microcracks of rocks rapidly expanded. The AE count rates of the dry specimens were significantly higher than those of the water-containing specimens. The peak value of the AE count rates of dry specimens ranged between 955 and 1,068 times/s, while the range of peak value was only 685 to 802 times/s in watersaturated specimens.

(4) In the failure phase, specimens began fracturing or collapsing, inflection points appeared in the stress-strain curve, the AE count rates exhibited sharp phase steps, and as the water content increased, the peak values of the respective $\mathrm{AE}$ count rates decreased. The time to reach the peak stress value of water-saturated specimens was increased as compared to that of AE count rate, as shown in the " $L$ " zone in Figure 5(c). This lagging phenomenon could be a definitive indicator and forecasting characteristic of rock mass fracturing and instability in engineered water-containing structures, such as a mine slope and dam body. 


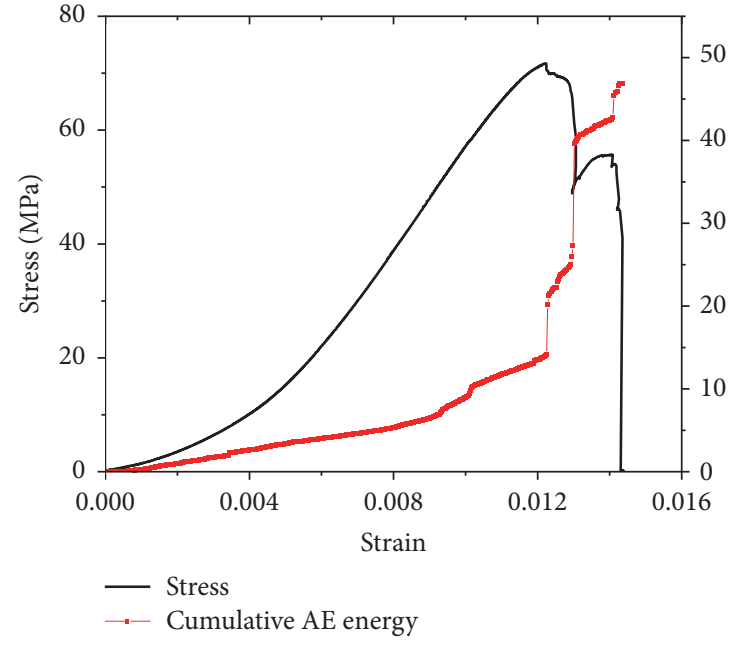

(a) G-1

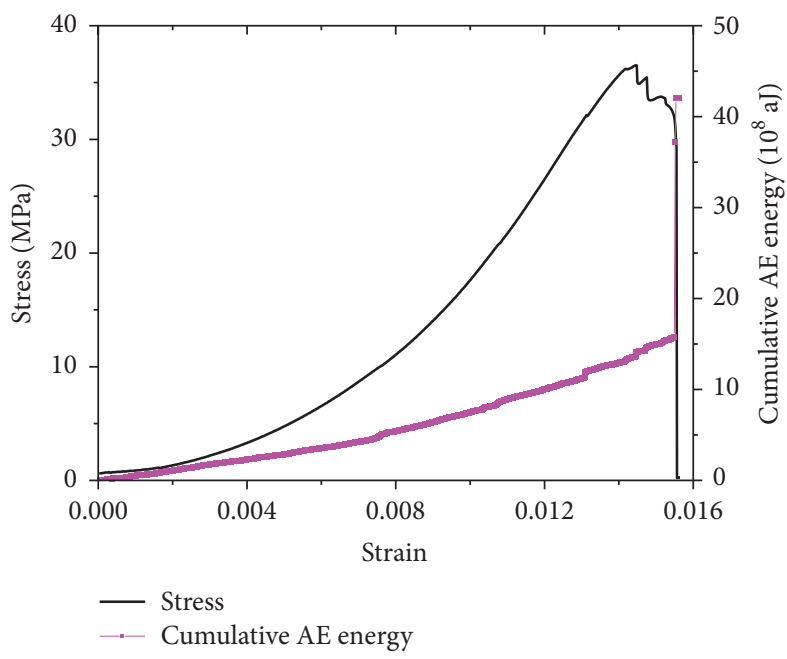

(b) Z-2

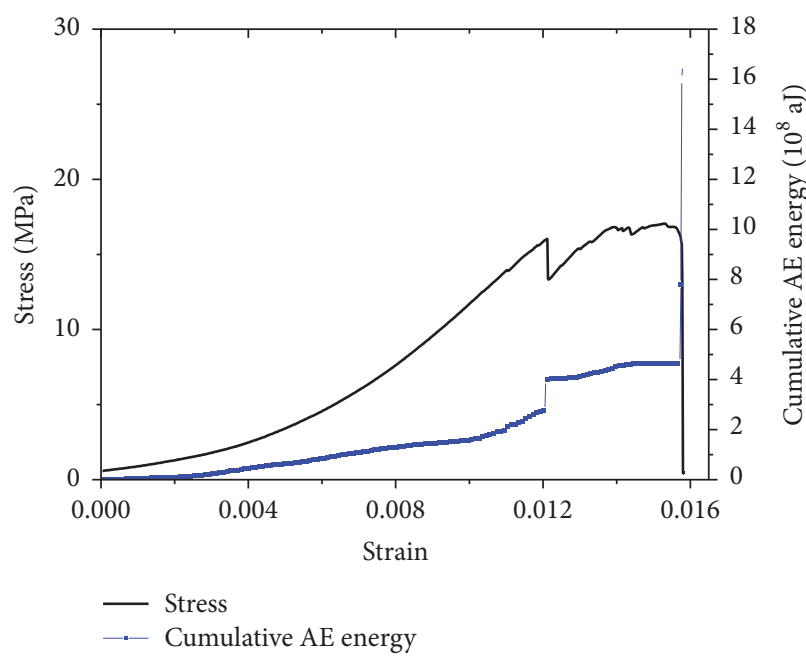

(c) B-3

FIGURE 7: Damage variable-strain curves of specimens.

3.4. AE Energy Features. The important parameters that characterize rock $\mathrm{AE}$ characteristics also include the $\mathrm{AE}$ absolute energy rate and cumulative $\mathrm{AE}$ energy. $\mathrm{AE}$ energy is a time integral of the squared $\mathrm{AE}$ voltage over the output resistance of the equipment, and it is proportional to the squared AE amplitude. The cumulative AE energy parameter was selected in this paper to characterize the internal energyreleasing process of siltstones under dry, natural, and watersaturated conditions when fractured under uniaxial compression. Figures 7(a), 7(b), and 7(c) demonstrate the variation curves of the cumulative AE energy according to the respective strains of the G-1, Z-2, and B-3 specimens while under uniaxial compression.

Figure 7 shows that the curve could characterize the energy release evolution rule observed during the fracture process of specimens. The cumulative AE absolute energy value significantly decreased as the water content increased. The cumulative AE absolute energy of the dry specimens was 1.12 times that of the natural specimens and 3.11 times that of the water-saturated specimens, which indicated that water yielded an effect on the energy release during the specimen fracture process. For the natural and water-saturated specimens, as water filled the internal microcracks of rocks, the energy released when cracks expanded was relatively low.

3.5. Comparative Analysis. To further investigate the effects of water content on $\mathrm{AE}$ count rate, the total $\mathrm{AE}$ count curve and cumulative AE energy curve of rocks under dry, natural, and water-saturated conditions were created. The horizontal axis represents the normalized relative time; the relationship curves are shown in Figures 8(a) and 8(b).Figure 8 illustrates the significant effects of water content on the total AE count and cumulative AE energy.

(1) The increase in water content decreased the AE cumulative events. The AE levels of the dry specimens were relatively high and there was a large amount of 


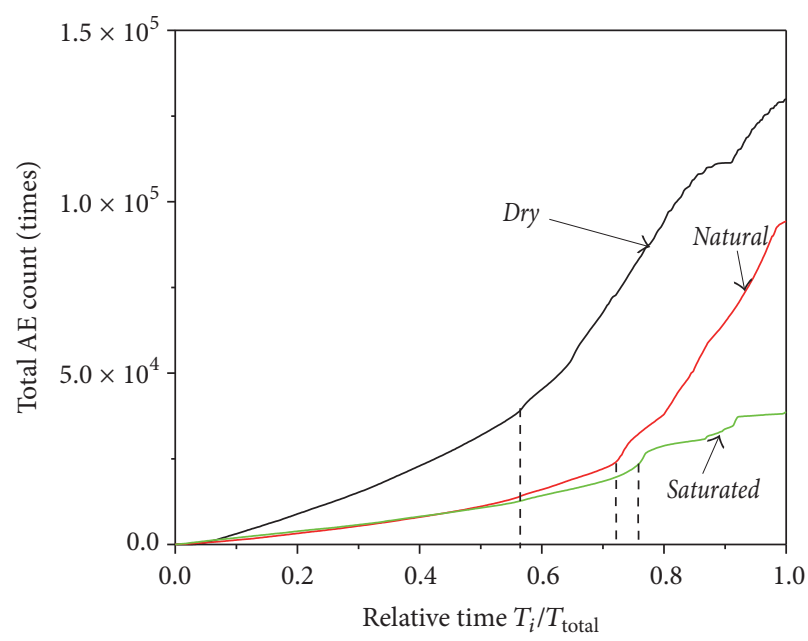

(a) Comparison between siltstones under different water contents in the total AE count

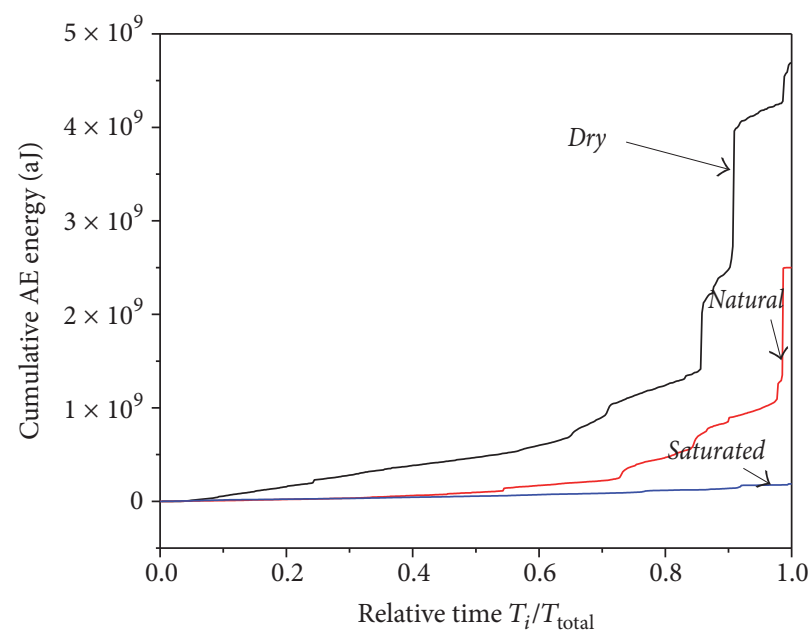

(b) Comparison between siltstones under different water contents in cumulative AE energy

FIGURE 8: Effects of water content on AE.

released energy and relatively high total AE count and cumulative AE energy.

(2) The total AE count curves and cumulative AE energy curves of the dry and natural specimens demonstrated a clear tendency of abrupt increase until the specimen exhibited complete fracture, which indicated that the rock fracture type was a brittle failure, that is, a "burst-type fracture." The abrupt increase appeared once in the curves of each of the watersaturated specimens, but each time a subsequent slow ascent until the specimens fractured was observed; this indicated that the rock fracture was a plastic failure, that is, a "steady-type fracture." As the water content of specimens increased, the point of time for the total AE count curves lagged gradually (Figure $8(\mathrm{a}))$.

(3) As compared to the water-containing specimens, the AE count rate of dry specimens exhibited significantly stronger fluctuations. The cumulative AE event count of the dry specimens was 1.15 times that of the natural specimens and 2.13 times that of the water-saturated specimens. The cumulative AE energy of the dry and natural specimens was higher than that of the watersaturated specimens by one order of magnitude.

3.6. Microanalysis of Internal Structure. To understand the effects of water content on the mechanical properties of siltstone on a microscopic level, rock SEM (Scanning Electron Microscope) was used to scan the siltstone specimens in the respective dry, natural, and water-saturated states; images of the respective microstructures were subsequently obtained. These images are shown in Figure 9 for each of the three water contents after amplification (1,000 times).

A comparison of the SEM images of siltstones between each of the three states shown in Figure 9 indicates that the water yielded effects on the respective microstructures. In the dry state, in situ microcracks and microjoints between particles were observed with different particle shapes and a disorderly arrangement; additionally, the interparticles were filled with cement (Figure 9(a)). In the natural state, the microstructures of the specimens changed; the cement expanded under the effects of water and surrounded the particles; cotton-shaped bodies consequently formed in the neighboring fine cavities between them (Figure 9(b)). In the water-saturated state, the cement expanded further, the particles were larger with an orderly arrangement, relatively large cracks formed, and the rock structure was loose (Figure 9(c)).

Siltstone is a cement-type sedimentary rock, and its mechanical properties are related to cement components and types. Clay minerals in siltstone are strongly hydrophilic; thus they experience anisotropic expansion after rapidly absorbing water, which subsequently affects the balance of the original internal rock stress. As the water content increases, the clay minerals further expand and generate local tensile stress. When the generated tensile stress is greater than the cohesion force between the siltstone particles, microcracks will form between the particles. As this occurs, a portion of the cement in the siltstone will dissolve when water is encountered, thus reducing the frictional force between particles and subsequently loosening the internal microstructure of the rock.

The aforementioned transformations are the primary reasons that the compressive strength, peak stress, and elasticity modulus of siltstone decrease when water is encountered and the rock undergoes a change from brittle to plastic failure under compression.

\section{Conclusions}

(1) The uniaxial compression failure of siltstone was categorized into the following four phases: in situ crack compacting phase, linear-elastic deformation phase, plastic yield deformation phase, and fracturing phase. Water content influenced the mechanical 


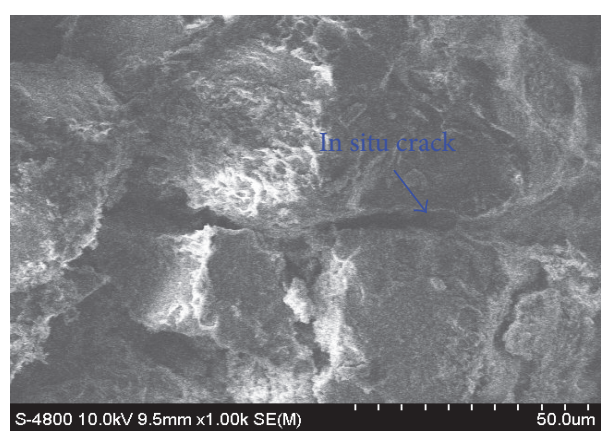

(a) Dry specimen

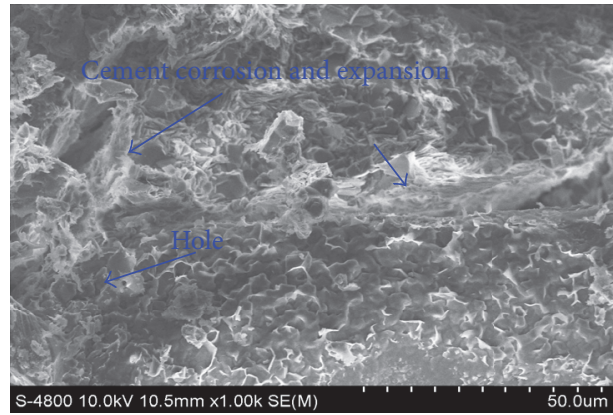

(b) Natural specimen

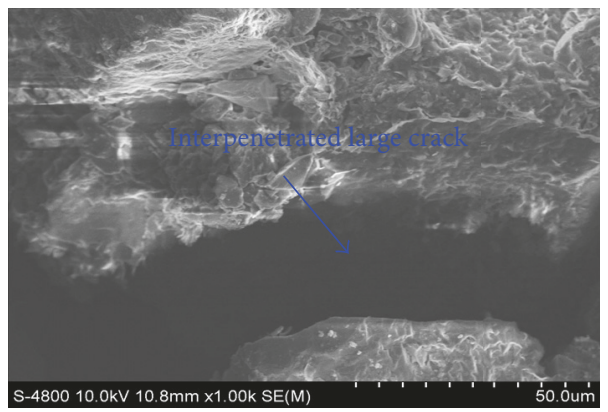

(c) Saturated specimen

FIGURE 9: SEM picture of siltstone.

properties of siltstone, and the compressive strength and elasticity modulus of the siltstone decreased as the water content increased.

(2) The uniaxial compression failure modes of the siltstone specimens according to water content are typical of the X-type shear failure. The X-type failure of dry and natural specimens was more apparent. As the water content increased, the failure severity of the siltstone specimens tended to decrease, which indicated that water exerted a softening effect on siltstone; thus, the specimens experienced the change from brittle to plastic failure.

(3) The uniaxial compression failure process of the siltstone specimens with varied water content yielded AE signal generation; the variation curve of the AE count rate was consistent with the stress-strain whole-process curve of siltstone failure. Water content affected the $\mathrm{AE}$ of siltstone, with the total $\mathrm{AE}$ count and cumulative AE energy value decreasing as the water content increased. The AE count rates of the dry specimens were significantly higher than those of the water-containing specimens; the cumulative AE energy of the dry specimens was 1.12 times that of the natural specimens and 3.11 times that of the water-saturated specimens, which indicated that water affected the internal structure of the specimens and that energy was released during the fracturing process. For water-saturated specimens, the time to reach the peak stress value was increased as compared to that of the peak value of the AE count rate; this lagging phenomenon is suggested to be a definitive indicator and forecasting characteristic of rock mass fracturing and instability in engineered water-containing structures, such as a mine slope and dam body.

(4) Water content affected the internal microstructure of the siltstone. The presence of water dissolved the cement between the microparticles of the siltstone; this cement subsequently surrounded the particle surface, thus reducing the frictional force between particles. The dissolution and deformation of cement gradually expanded the in situ microcracks in the siltstone until relatively large cracks formed and the mechanical strength of siltstones decreased.

(5) The failure processes of the rocks utilized in this study were also influenced by multiple factors, such as the confining pressure and loading and unloading modes. Therefore, further in-depth research is required.

\section{Conflicts of Interest}

The authors declare that they have no conflicts of interest.

\section{Acknowledgments}

The authors are grateful for the financial support from the "Five twelve" National Science and Technology Support Program of China (no. 2013BAB48B02), the Specialized Research Foundation for the Doctoral Program of Higher Education 
(20120023110023), and Fundamental Research Funds for the Central Universities (no. 2014QZ03).

\section{References}

[1] J.-S. Kim, K.-S. Lee, W.-J. Cho, H.-J. Choi, and G.-C. Cho, "A comparative evaluation of stress-strain and acoustic emission methods for quantitative damage assessments of brittle rock," Rock Mechanics and Rock Engineering, vol. 48, no. 2, pp. 495508, 2014.

[2] X.-J. Tang, J. Xu, and T. Deng, "Research on the rock acoustic emission rules under different experimental conditions," Applied Mechanics and Materials, vol. 170-173, pp. 237-241, 2012.

[3] M. Rao, D. Murthy, G. Nagaraja Rao, S. K. Mohanty, and S. Udayakumar, "Stress-induced micro-cracking and brittle failure of Godhra granite, Gujarat: a laboratory investigation using acoustic emission," Journal of the Geological Society of India, vol. 64, no. 6, pp. 775-783, 2004.

[4] V. A. Mansurov, "Acoustic emission from failing rock behaviour," Rock Mechanics and Rock Engineering, vol. 27, no. 3, pp. 173-182, 1994.

[5] T. Ishida, T. Kanagawa, and Y. Kanaori, "Source distribution of acoustic emissions during an in-situ direct shear test: implications for an analog model of seismogenic faulting in an inhomogeneous rock mass," Engineering Geology, vol. 110, no. 3-4, pp. 66-76, 2010.

[6] Z. A. Moradian, G. Ballivy, P. Rivard, C. Gravel, and B. Rousseau, "Evaluating damage during shear tests of rock joints using acoustic emissions," International Journal of Rock Mechanics and Mining Sciences, vol. 47, no. 4, pp. 590-598, 2010.

[7] B. J. Pestman and J. G. Van Munster, "An acoustic emission study of damage development and stress-memory effects in sandstone," International Journal of Rock Mechanics and Mining Sciences and Geomechanics, vol. 33, no. 6, pp. 585-593, 1996.

[8] E. Aker, D. Kühn, V. Vavryčuk, M. Soldal, and V. Oye, "Experimental investigation of acoustic emissions and their moment tensors in rock during failure," International Journal of Rock Mechanics and Mining Sciences, vol. 70, pp. 286-295, 2014.

[9] R. P. Janeiro and H. H. Einstein, "Experimental study of the cracking behavior of specimens containing inclusions (under uniaxial compression)," International Journal of Fracture, vol. 164, no. 1, pp. 83-102, 2010.

[10] M. V. M. S. Rao and K. J. Prasanna Lakshmi, "Analysis of b-value and improved b-value of acoustic emissions accompanying rock fracture," Current Science, vol. 89, no. 9, pp. 1577-1582, 2005.

[11] X. Zhao, Y. Li, R. Yuan, T. Yang, J. Zhang, and J. Liu, "Study on crack dynamic propagation process of rock samples based on acoustic emission location," Chinese Journal of Rock Mechanics and Engineering, vol. 26, no. 5, pp. 944-950, 2007.

[12] M. S. A. Perera, P. G. Ranjith, and M. Peter, "Effects of saturation medium and pressure on strength parameters of Latrobe Valley brown coal: carbon dioxide, water and nitrogen saturations," Energy, vol. 36, no. 12, pp. 6941-6947, 2011.

[13] V. Vishal, P. G. Ranjith, and T. N. Singh, "An experimental investigation on behaviour of coal under fluid saturation, using acoustic emission," Journal of Natural Gas Science and Engineering, vol. 22, pp. 428-436, 2015.

[14] X.-N. Wang, C.-P. Lu, J.-H. Xue et al., "Experimental research on rules of acoustic emission and micro seismic effects of burst failure of compound coal-rock samples," Rock and Soil Mechanics, vol. 34, no. 9, pp. 2569-2575, 2013.
[15] J. Guo, G.-R. Feng, Y.-X. Guo et al., "Mechanical property variation under dynamic uniaxial compression and micro-mechanism of lamprophyre in saturated state," Journal of the China Coal Society, vol. 40, no. 2, pp. 323-330, 2015.

[16] M. R. Vergara and T. Triantafyllidis, "Influence of water content on the mechanical properties of an argillaceous swelling rock," Rock Mechanics and Rock Engineering, vol. 49, no. 7, pp. 25552568, 2016.

[17] J. Kodama, T. Goto, Y. Fujii, and P. Hagan, “The effects of water content, temperature and loading rate on strength and failure process of frozen rocks," International Journal of Rock Mechanics and Mining Sciences, vol. 62, no. 3, pp. 1-13, 2013.

[18] M. Z. Abu Bakar, Y. Majeed, and J. Rostami, "Effects of rock water content on CERCHAR Abrasivity Index," Wear, vol. 368369, pp. 132-145, 2016.

[19] M. Aziz, I. Towhata, S. Yamada, M. U. Qureshi, and K. Kawano, "Water-induced granular decomposition and its effects on geotechnical properties of crushed soft rocks," Natural Hazards and Earth System Science, vol. 10, no. 6, pp. 1229-1238, 2010.

[20] Z. Cuiying, D. Yimei, T. Xiangshao et al., "Testing study on variation regularities of solution components in saturation of soft rocks," Chinese Journal of Rock Mechanics and Engineering, vol. 36, no. 12, pp. 3813-3817, 2004.

[21] C.-Y. Zhou, X.-S. Tan, Y.-M. Deng, L.-M. Zhang, and J.-H. Wang, "Research on softening micro-mechanism of special soft rocks," Chinese Journal of Rock Mechanics and Engineering, vol. 24, no. 3, pp. 394-400, 2005.

[22] Y. Kang, X. Wang, X. Yang, and B. Yuan, "Numerical simulation of control blasting with borehole protecting and water jet slotting in soft rock mass," Disaster Advances, vol. 5, no. 4, pp. 933-938, 2012.

[23] T. Heggheim, M. V. Madland, R. Risnes, and T. Austad, "A chemical induced enhanced weakening of chalk by seawater," Journal of Petroleum Science and Engineering, vol. 46, no. 3, pp. 171-184, 2005.

[24] C.-H. Yang, H.-J. Mao, X.-C. Wang, X.-H. Li, and J.-W. Chen, "Study on variation of microstructure and mechanical properties of water-weakening slates," Rock and Soil Mechanics, vol. 27, no. 12, pp. 2090-2098, 2006.

[25] A. S. Voznesenskii, E. A. Ertuganova, S. V. Vil'yamov, and M. N. Tavostin, "Studying the mechanism of acoustic emission in failure of rock salt by dissolving," Journal of Mining Science, vol. 42, no. 1, pp. 35-42, 2006.

[26] J.-H. Deng, X.-C. Huang, J.-B. Peng, and B.-X. Chen, "Mechanical properties of Gypsum Breccia with different water contents," Chinese Journal of Geotechnical Engineering, vol. 30, no. 8, pp. 1203-1207, 2008.

[27] Z. A. Erguler and R. Ulusay, "Water-induced variations in mechanical properties of clay-bearing rocks," International Journal of Rock Mechanics and Mining Sciences, vol. 46, no. 2, pp. 355-370, 2009.

[28] H. Qin, G. Huang, and W. Wang, "Experimental study of acoustic emission characteristics of coal samples with different moisture contents in process of compression deformation and failure," Chinese Journal of Rock Mechanics and Engineering, vol. 31, no. 6, pp. 1115-1120, 2012.

[29] V. L. Shkuratnik, Y. L. Filimonov, and S. V. Kuchurin, "Regularities of acoustic emission in coal samples under triaxial compression," Journal of Mining Science, vol. 41, no. 1, pp. 4452, 2005.

[30] Q.-L. Yao, X.-H. Li, L.-H. He, and J. Zhou, "Strength deterioration and acoustic emission characteristics of water-bearing 
sandstone in uniaxial compressive experiment," Journal of Mining and Safety Engineering, vol. 30, no. 5, pp. 717-722, 2013.

[31] Y.-B. Zhang, X.-H. Huang, S.-S. Li, and X.-X. Liu, "Spectral character analysis of sandstone under saturation condition in rupture procedure," Rock and Soil Mechanics, vol. 34, no. 6, pp. 1574-1578, 2013.

[32] V. Rudajev, J. Vilhelm, and T. Lokajíček, "Laboratory studies of acoustic emission prior to uniaxial compressive rock failure," International Journal of Rock Mechanics and Mining Sciences, vol. 37, no. 4, pp. 699-704, 2000. 

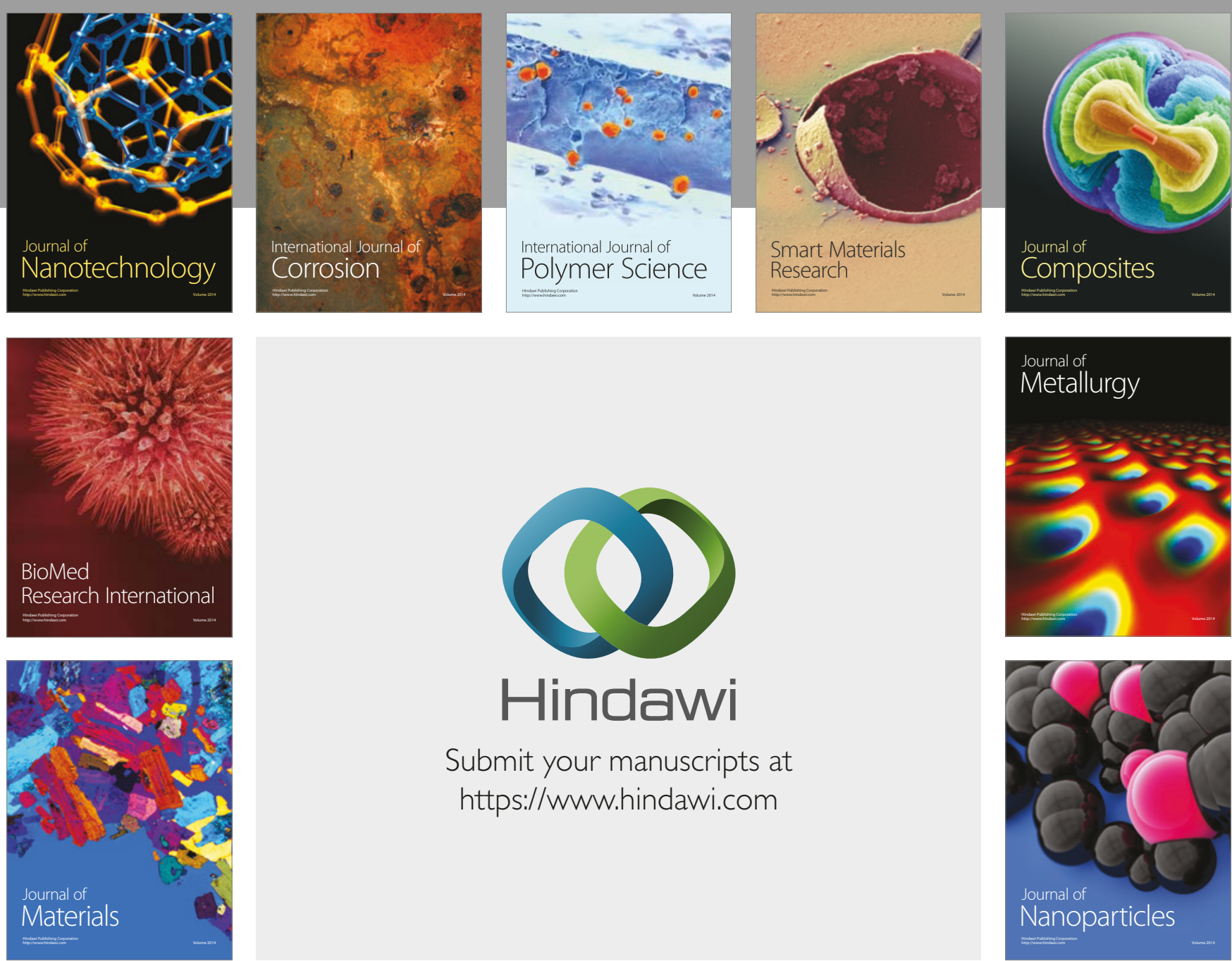

\section{Hindawi}

Submit your manuscripts at

https://www.hindawi.com
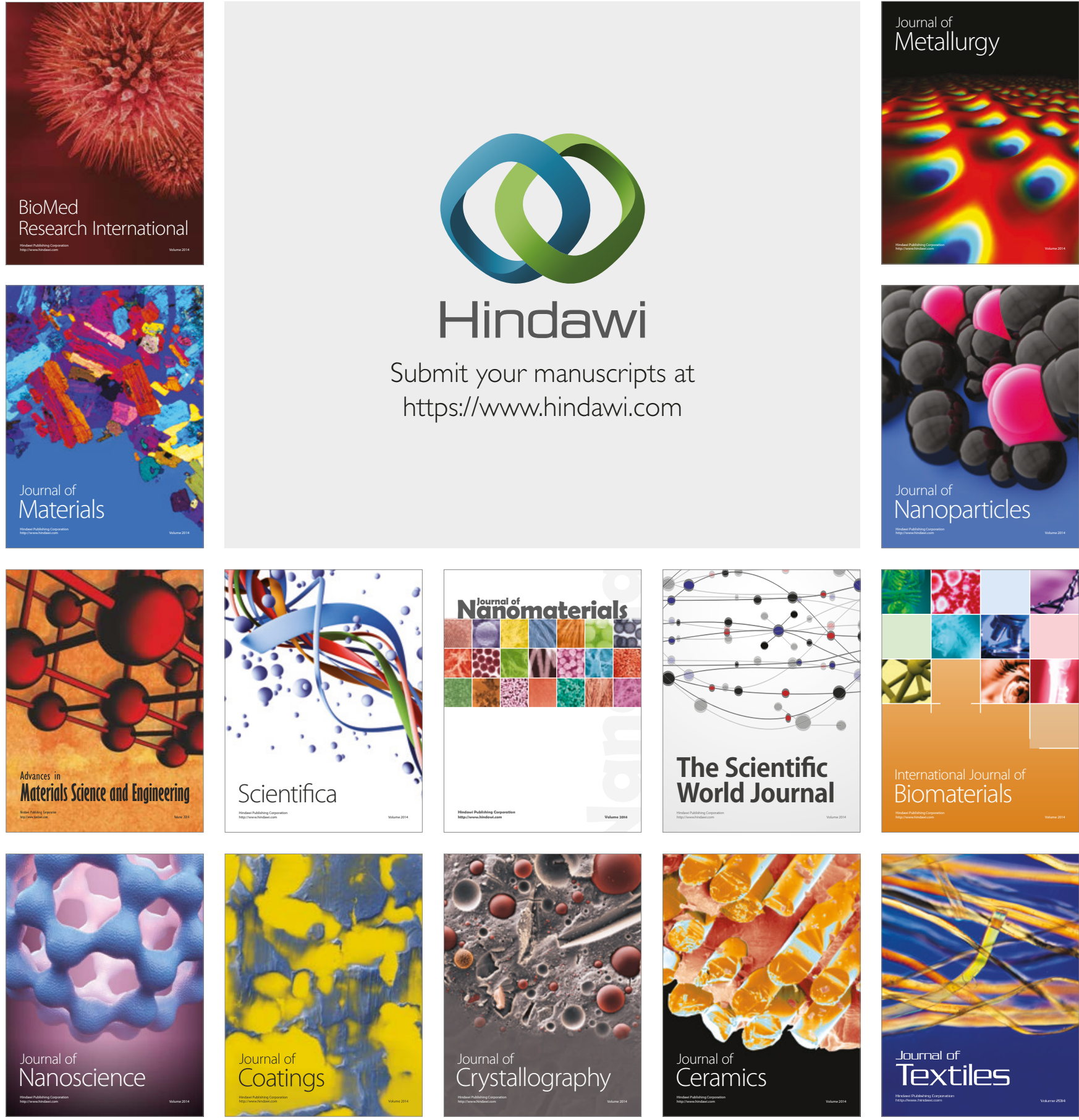

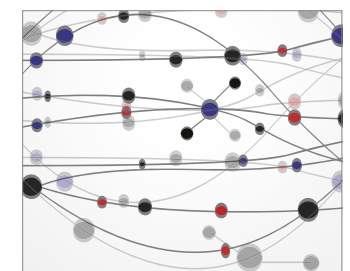

The Scientific World Journal
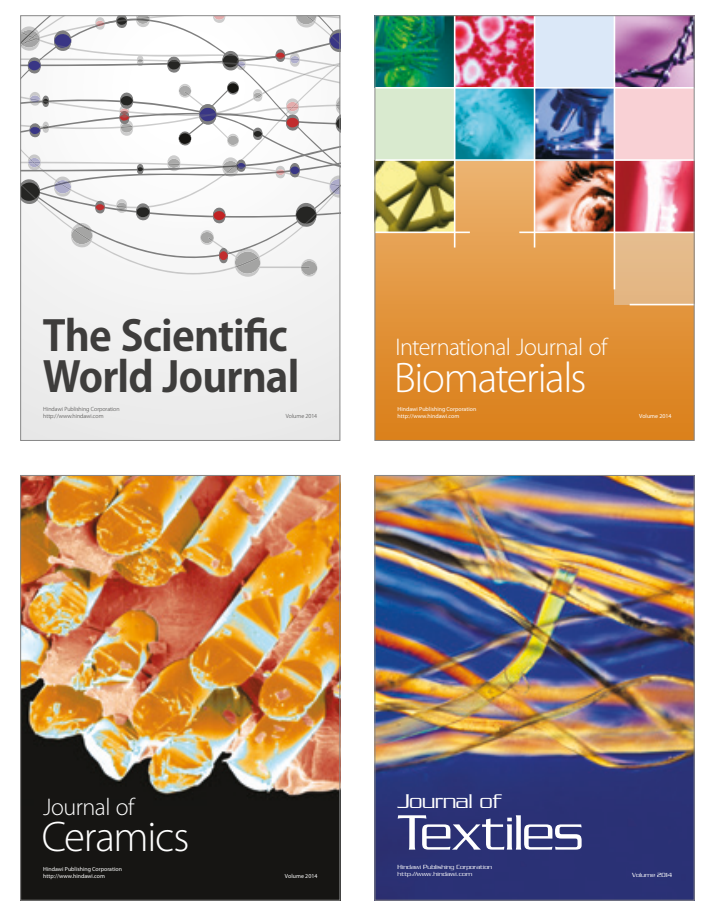